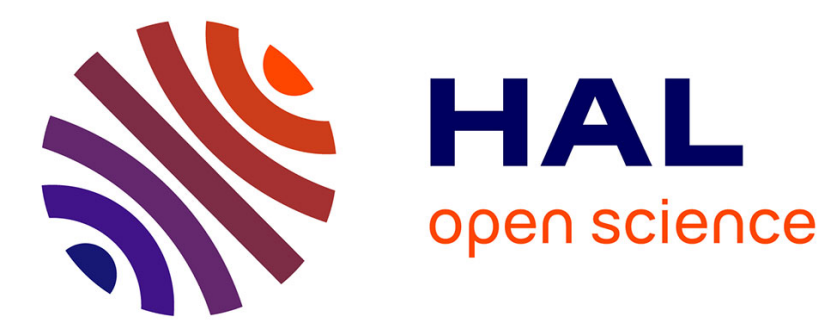

\title{
Sharing the design of a cognitive tool between researchers and potential users
}

Lorène Prost, Marianne Cerf, Marie-Helene Jeuffroy

\section{To cite this version:}

Lorène Prost, Marianne Cerf, Marie-Helene Jeuffroy. Sharing the design of a cognitive tool between researchers and potential users. European Conference on Cognitive Ergonomics: Invent! Explore!, Aug 2007, London, United Kingdom. 8 p. hal-01173143

\section{HAL Id: hal-01173143 \\ https://hal.science/hal-01173143}

Submitted on 6 Jun 2020

HAL is a multi-disciplinary open access archive for the deposit and dissemination of scientific research documents, whether they are published or not. The documents may come from teaching and research institutions in France or abroad, or from public or private research centers.
L'archive ouverte pluridisciplinaire HAL, est destinée au dépôt et à la diffusion de documents scientifiques de niveau recherche, publiés ou non, émanant des établissements d'enseignement et de recherche français ou étrangers, des laboratoires publics ou privés. 


\section{Sharing the design of a cognitive tool between researchers and potential users}

\author{
Lorène Prost \\ UMR INRA-AgroParisTech \\ Agronomie \\ BP1 \\ F-78 850 Thiverval Grignon \\ prost@grignon.inra.fr
}

\author{
Marianne Cerf \\ UMR INRA-AgroParisTech \\ SAD-APT \\ BP1 \\ F-78 850 Thiverval Grignon \\ cerf@agroparistech.fr
}

\author{
Marie-Hélène Jeuffroy \\ UMR INRA-AgroParisTech \\ Agronomie \\ BP1 \\ F-78 850 Thiverval Grignon \\ jeuffroy@grignon.inra.fr
}

\begin{abstract}
Motivation - Learning from the shared design process of a cognitive tool: how it promotes changes in designers' activities as well as in those of potential users, and how the tool evolves in such a process.

Research approach - Three groups of potential users worked in interaction with agronomist researchers who had designed the tool's concepts, and ergonomists who assisted them in building this interaction and in the debriefings. After explorative surveys to build a prototype of the cognitive tool in line with users' activities, this prototype was used in collective groups of agronomists and potential users and then put into the hands of the users for a two-week period to give them a personal view of the tool. Data collected during this "test" period were then analysed to further develop the tool and to discuss with the users the changes they encountered in their activity, in relation to the process as a whole.
\end{abstract}

Findings/Design - The interface but also the concepts underlying the tool were altered profoundly, thus raising new scientific questions for agronomists. The users developed a new understanding of their cognitive task. We suggest that this was achieved by (i) group discussions around the prototype between actors with diverse points of view; and (ii) the way the users were asked to "play" with the prototype by focusing specifically on cognitive dimensions of their activity.

Take-away message - We explored three dimensions of tool design, namely crystallization, plasticity and development, as well as their evolution over time. This we did by examining a cognitive task, along with a prototype for supporting it, in a dialogical process between potential users and designers.

Keywords

Cognitive tool, design, participation, agriculture

\section{INTRODUCTION}

In agriculture, new cultivars (or varieties) have always been a key element in the development of new production systems. The assessment of new cultivars' behaviour against a diversity of environments (soil, climate and means of production) is a key issue for the actors along the chain linking plant breeders to food suppliers. During the 90's, researchers have designed a theoretical model to assist these actors in assessing wheat cultivar behaviour by enabling them to make the most of information that they collect on their cultivars in all their environments (Brancourt-Hulmel, Lecomte, \& Meynard, 1999; Lecomte, 2005). But experience shows that the transition from a model to a tool-in-use is tricky: many models produced by agronomist researchers have remained research tools and have not become operational for non-researchers. That is why the agronomists involved in this study chose to work with ergonomists in order to test a different type of work with potential users of their tool. 
Ergonomists interested in design recognized a long time ago that any tool implements a model of both its use and its user. Building stairs, for instance, is based on a model of a valid person or a valid person with no heavy or rolling luggage. Thus, as Béguin points out (2007), the tool crystallizes a model of the user and his/her activity. The challenge is then to avoid crystallizing a model which hampers the user's activity. Work analysis or simulation can be relevant to identify key features of the activity and to keep them as such while building the tool. But full anticipation of the activity is never possible. It is also well known that users are creative and that this creativity is necessary to deal with the intrinsic variability of working situations. Furthermore, potential users have varying characteristics and abilities, so that the same person can behave differently due to stress or tiredness for instance. Therefore, Béguin (ibid), following other authors, emphasizes the need for some plasticity of the tool. It should fit a diversity of situations and persons while defining the borders within which the use remains valid and safe. Achieving this still depends on work analysis or simulation, although those ones aim at identifying the leeway that needs to be left to the users and the diversity of the situations of use. Finally, Béguin (ibid.) suggests a third perspective for a design process: a developmental one arguing that "there is no tool without inventiveness but no use without re-inventiveness!" He suggests that such a developmental perspective rests on users' participation in the design process. The way in which such participation can actually result in codevelopment of the tool and of the users' activity is to be worked out in each given situation. Although participation is often promoted in computer design approaches such as Scandinavian participatory design or user-centred design methods (Bodker, Gronbaek, \& Kyng, 1993), the question of a joint development of the tool and the activity arises less often (Henderson, 1991; Béguin,

2003)

and

even

less so

when it

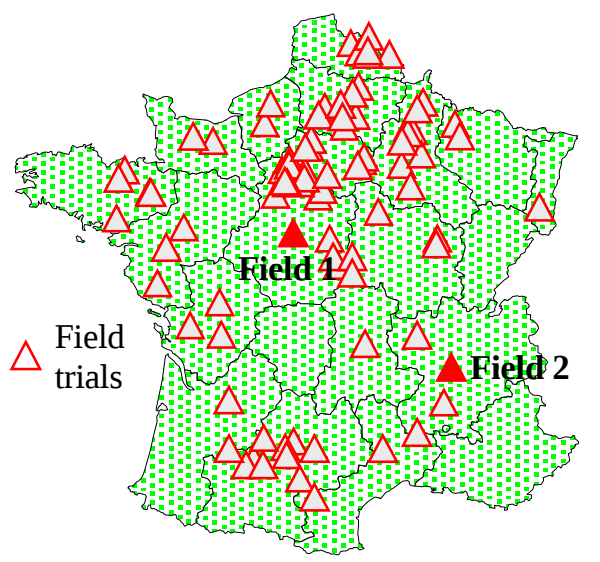

Example of a network of field trials (NFT): network all over France, with 5 cultivars grown in each field trial concerns the development of the activity of both users and designers. How, then, can we deal with participation issues so that participation can produce such codevelopment?

We chose to organize participation by putting the designed prototype and the analysis of users' activities at the core of a dialogical process between researchers and users. Our intention was to build a shared design process in which both techniques (using the prototype in the design and analysing activities) fulfil the mediation function as developed by Vygotski (1978). As a potential tool used by actors to assess cultivars' behaviour, the prototype could serve that purpose for these actors. Actually, as shown by Engeström (1987) and Miettinen (2000) for more stabilized tools, the prototype can disturb the whole activity system by producing contradictions that can lead the entire system to evolve. Moreover, the analysis of users' activities might become a tool for the researchers whose object is actually the prototype, as they have to implement a model of use and users within the prototype. We suggest that such a symbolic tool can disturb researchers' modelling activity. But the question is then to identify how such techniques have to be introduced and used in the design situation so that expansion occurs in both activity systems and reveals some needed changes in the prototype.

Accordingly, our study had two objectives: (i) finding a design strategy combining crystallization, plasticity and development issues and, more specifically, allowing codevelopment of the tool and of the activity; (ii) checking how the design process promotes changes in the activities of all the participants involved in the design process.

\section{METHODOLOGY \\ The tool}

Output 1: Using the differences at the scale of the NFT to characterize the limiting factors (LF) of the yield

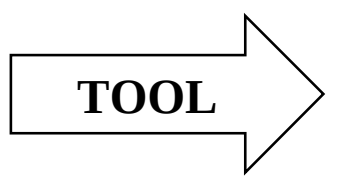

Output 2: Linking the differences of cultivar behaviour in the NFT with the LF to assess the resistance of the new cultivars to the LF
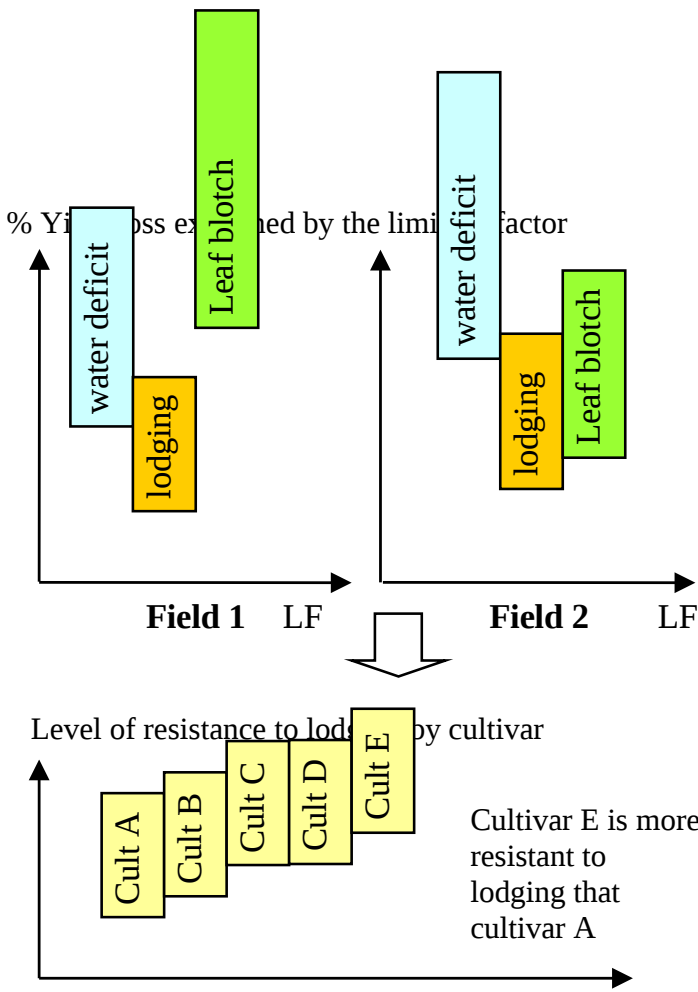
To assess the behaviour of cultivars against different environments, various actors build big networks of field trials (NFT). Such NFT are composed of trials located in different soil and climatic environments, as shown in Figure 1. Each trial is carried out according to a protocol that defines the shape of the trial (number of repetitions for each cultivar as well as number of tested cultivars, for example) and the cropping techniques used to grow the cultivars (sowing date, amount of nitrogen fertilizer, date of application, and so on). During the 90's, researchers have designed a model for the analysis of information derived from such NFT. While actors usually compare the cultivars according to their respective yield performance and pest and disease resistance, this model is designed to use the information from all of the NFT trials, in order to (i) fully characterize the factors which limited the yield of well-known cultivars in a given trial, (ii) identify the complementarity of the NFT environments (those sharing the same limiting factors or those showing very specific limiting factors for instance), and (iii) characterize the behaviour of the new cultivars assessed in the NFT against the limiting factors which appeared in it. Figure 1 shows some of the graphical outputs of the model: Output 1 shows the \% of yield loss explained by different limiting factors, and Output 2, the appraisal of a cultivar's resistance to various limiting factors.

\section{The actors}

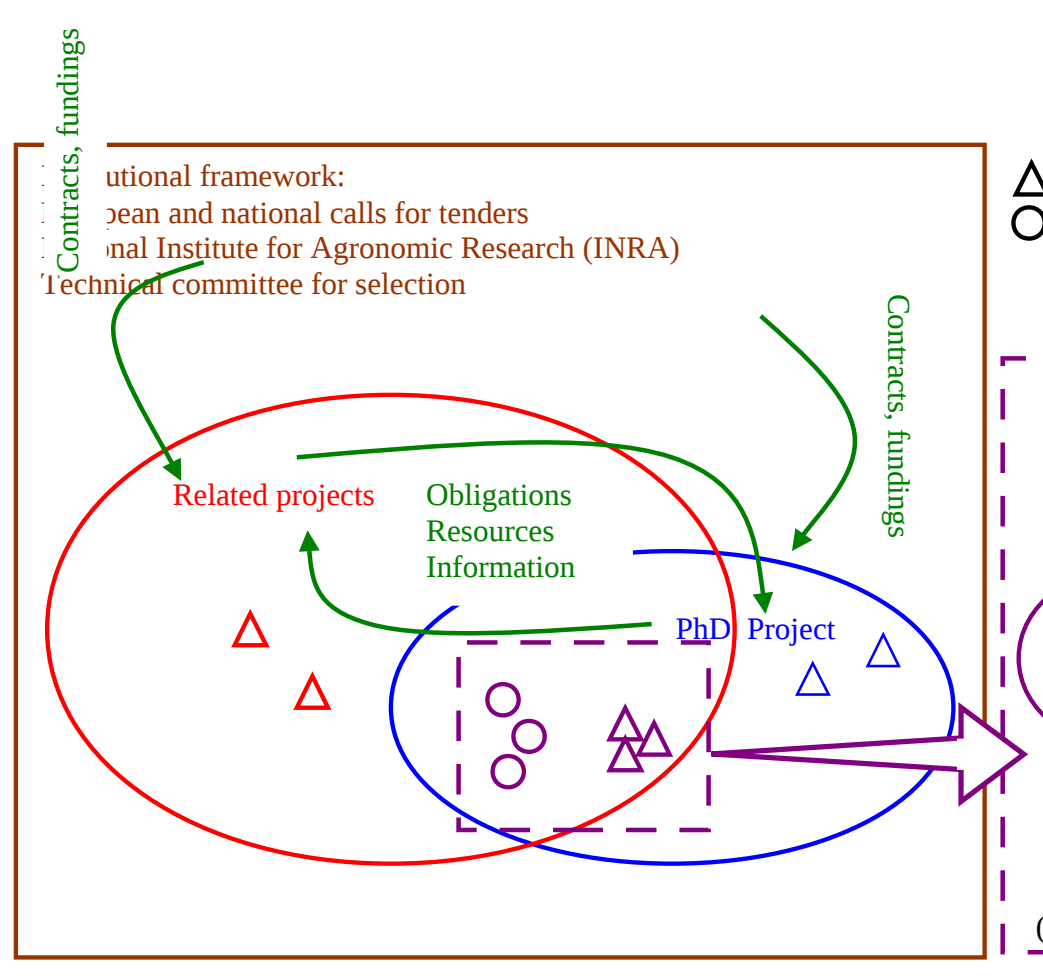

Three researchers were involved in this work based on a pluridisciplinary $\mathrm{PhD}$ project: an agronomist and an ergonomist supervised a student whose position was between agronomy and ergonomy. A statistician and a geneticist also took part in the project occasionally. Three groups of potential users of the model were identified after a first set of interviews: (1) a group of plant breeders who wanted more information on the new cultivars they were breeding, (2) people in charge of national examination of the new cultivars (which is compulsory for commercializing cultivars in France), who wanted to improve their examination, and (3) agents from the French Technical Institute for Cereals who wanted to improve their knowledge of cultivars in order to give farmers better advice on choosing cultivars. Although these three groups of actors worked in close interaction, they had different objectives. For this reason we worked with all of them but in parallel (e.g. in different meetings) to avoid any problem of confidentiality. Within each group, several people took part in the work. For instance, the group of seed breeders included people in charge of the plant breeding and those in charge of the commercialization of the newly-bred cultivars.

As shown in Figure 2, we built various links with users and users' organizations: funding resources were jointly sought to achieve some specific objectives more or less linked to the $\mathrm{PhD}$ project; and contractual agreements were discussed with each organization in order to specify
Figure 2: the organization of the various partners the aim of the collaboration, the people to involve in the collaborative work, and the way to perform it. We were 
also bound by some INRA requirements, as it had funded the $\mathrm{PhD}$ work. All these

different links framed the interactions we managed to develop among users and researchers. The impact of such a frame on the whole process still needs further investigation.

\section{Design strategy}

We call design strategy the way in which we tried to develop efficient interactions among researchers and users to co-develop the tool and the users' and researchers' activities, while keeping in mind crystallization and plasticity. More precisely, this strategy is based on 4 stages spread over a three-year period and aims at building interactions which enable: (i) users to question the agronomists' model, (ii) researchers to acknowledge the way actors assess cultivars in their respective working situations, and (iii) users to question their own activity regarding the cognitive dimension of the task of assessing various cultivars' behaviour as they were analysing the information produced in NFT.

Stage 1 was meant to transform the agronomists' theoretical model into an operational prototype. This was achieved through an analysis of users' activities regarding NFT (Lecomte, 2005). Attention was paid to the data that users collected on NFT and how these data fitted the inputs of the model. We also collected data on their current tools and objectives for analysing the information produced by the NFT, and their own way of carrying out such analysis. Secondly, we discussed with potential users the current functionalities that the agronomic model could offer.

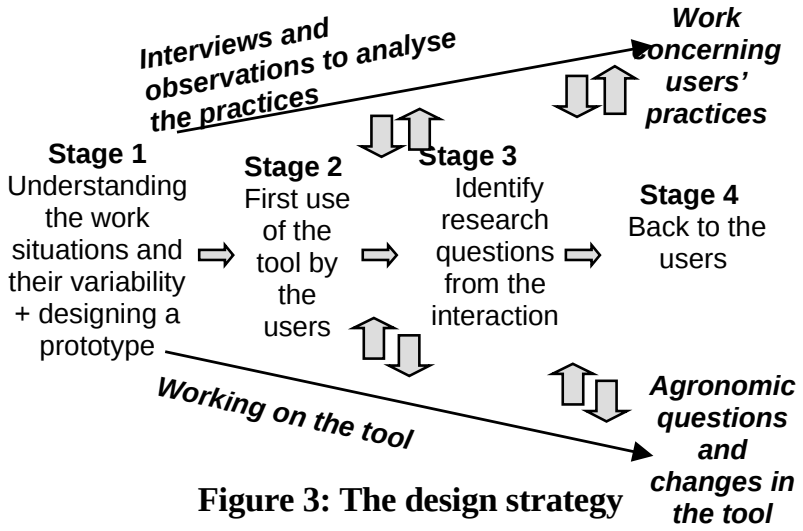

This first phase was mainly focused on crystallization and plasticity. In fact, the analysis of users' activity and the construction of a prototype were a way of building or in other words crystallizing- a model of activity and use. They were also a way of understanding the variability of users' activities and uses, so that they could be taken into account in the technical specifications of the tool.

Stage 2 was organized to promote debates around the prototype among the different participants of the design process. The prototype was put into use, following the idea that simulation of use leads to rich interactions for design. We firstly organized collective meetings (e.g. with all participants of each group of potential users as described above). We explained to them the functionalities of the prototype and let the participants run the software on their own databases (e.g. data collected on their own NFT), discover the results of the analysis, and discuss with others the first problems they faced. Each participant was then given a software prototype and asked to test it against various sets of their own databases (e.g. they each had to choose on which set of cultivars and environments they wanted to obtain an assessment of cultivar behaviours) during a two- to threeweek period. We did not ask them to use the prototype in real time and real work situations, nor to use it in preestablished use scenarios. They were only asked to keep track of the sets of data they analysed and of their understanding of the software's outputs. After this period, we organized collective debriefings to identify

\begin{tabular}{|c|c|c|c|c|}
\hline & Stage 1 & Stage 2 & Stage 3 & Stage 4 \\
\hline crystallization & \multirow{2}{*}{$\begin{array}{l}\text { Building a model of } \\
\text { use and user } \\
\text { Identifying the } \\
\text { diversity of users' } \\
\text { activities to build } \\
\text { the specifications }\end{array}$} & & $\begin{array}{l}\text { Checking the need to improve } \\
\text { the model of activity }\end{array}$ & \\
\hline plasticity & & $\begin{array}{l}\text { Putting the prototype into use to } \\
\text { question its ability to fit various users' } \\
\text { way to assess cultivars in NFT }\end{array}$ & $\begin{array}{l}\text { Identifying the variability of } \\
\text { data ranges for which the tool } \\
\text { had to be reliable }\end{array}$ & \\
\hline development & & $\begin{array}{l}\text { Using the prototype to allow the users } \\
\text { to manipulate, appropriate and } \\
\text { criticize researchers' point of view. } \\
\text { Requesting users to use the prototype } \\
\text { out of their work routines to allow } \\
\text { them to question these routines. }\end{array}$ & $\begin{array}{l}\text { Using the users' remarks to } \\
\text { develop the modelling activity } \\
\text { of agronomists }\end{array}$ & $\begin{array}{l}\text { Interviews as a } \\
\text { reflexive tool on the } \\
\text { appropriation process } \\
\text { (users) and on the } \\
\text { design strategy } \\
\text { (researchers) }\end{array}$ \\
\hline
\end{tabular}


the problems they encountered and the expectations they had regarding the software's use.

This phase was directed more towards the plasticity of the tool by putting it into use, and towards the development of users' activities by organizing collective debates on their respective use of the tool and the problems they faced. We questioned them extensively during the debriefing meetings to relate what they said about the prototype to their activities: their tools, their objectives, their organization and so on. Through this process, we wished to support actors' reflexivity on their routines as well as their understanding of the researchers' point of view (as defined by Prieto, 1975).

Stage 3 was based on an exhaustive transcription of the collective discussions. This transcription was then used to conduct discussion among agronomists. The aim was to allow them to bring up relevant agronomic research questions relative to the way in which actors handled their data with the software, and the questions which they raised in collective discussions on the software and its potential use. Agronomists identified questions about the theoretical concepts implemented in the software and started to study alternative statistical and conceptual possibilities to be implemented later.

This stage allowed the researchers to gain more insight into the cognitive tasks carried out by the users while appropriating the tool to assess cultivars' behaviour. This was meant to allow them to eventually change their way of modelling the use and the users and of opening opportunities for the users to adjust the tool's use to their own situations. This stage was also meant to develop the agronomists' activities by affording them the opportunity to discuss how actors appropriated and questioned the

\begin{tabular}{|c|c|c|c|}
\hline & Interface & $\begin{array}{c}\text { Agronomic } \\
\text { questions }\end{array}$ & $\begin{array}{c}\text { Ergonomic } \\
\text { remarks }\end{array}$ \\
\hline $\begin{array}{l}\text { For each } \\
\text { meeting } \\
\text { of the } 3 \\
\text { groups of } \\
\text { partners }\end{array}$ & $\begin{array}{l}\text { Points linked } \\
\text { with interface } \\
\text { problems } \\
\text { e.g.: "you } \\
\text { should } \\
\text { homogenize } \\
\text { the colour } \\
\text { code of the } \\
\text { cultivars, it } \\
\text { is } \\
\text { disturbing!" }\end{array}$ & $\begin{array}{l}\text { Points that raise } \\
\text { agronomic or } \\
\text { statistical } \\
\text { questioning } \\
\text { e.g.: "How can } \\
\text { we be sure } \\
\text { that the model } \\
\text { points out all } \\
\text { the limiting } \\
\text { factors?" }\end{array}$ & $\begin{array}{l}\text { Points linked with } \\
\text { the use of the tool: } \\
\text { exploration, } \\
\text { imagined uses, } \\
\text { possible changes } \\
\text { e.g.: "we could } \\
\text { create another } \\
\text { trial, just to } \\
\text { collect all the } \\
\text { information } \\
\text { needed by the } \\
\text { tool" }\end{array}$ \\
\hline
\end{tabular}

functioning of the tool.

Stage 4 consisted in debriefing with each person participating in the whole process. We firstly went through the different steps of our joint work and pointed out those which were relevant for the interviewee. We secondly discussed the changes that the interviewee recalled in his/her activity system during this period of joint work and pointed out those that (s)he linked to the interactions we had around the prototype.
This stage was mainly oriented towards the development of users' activity by trying to support their Table 2: Grid to record the exchanges of STAGE 2

reflexivity on the appropriation process. The aim was also to ourselves be reflexive on the design strategy.

\section{RESULTS AND DISCUSSION}

\section{Some results of the design strategy stage by stage}

Stage 1 firstly resulted in the construction of a prototype that crystallized a use model: data collection to feed the model was viewed as a problem to be solved with experimenters (see below), and data analysis was viewed as sorting all the limiting factors which appeared in the NFT irrespective of its size. Some leeway was given to the users by providing three phases of calculation (a phase to calculate the global intensity of limiting factors, one to sort the limiting factors for a given trial and one to interpret each cultivar behaviour against these limiting factors) as the users were differently interested in each phase. The interface was also designed to give some flexibility to the tool (by allowing for some choices, giving different graphical views of the results and so on).

This stage also showed that some inputs of the tool might be difficult to obtain in the users' NFT. For example, discussions arose about the indicator used in the model to assess the nitrogen status of cultivars. The users told the agronomists that they would not be able to obtain the indicator, although they valued the way it was used in the software and the information it could produce on cultivar behaviour. To meet the experimenters' constraints, the agronomists carried out a field experiment and tested a new and easier way to measure the required indicator in the field.

During Stage 2, both the tool's interface and its conceptual model were assessed and commented on by the users, who also questioned their own activities and made some proposals for improving the use value of the tool. We gathered a huge number of comments that we sorted into three classes: those dealing with interface design, those dealing with questions about the conceptual model and its results, and those dealing with use issues. We gathered questions but also some proposals made by users to solve them. These data need to be analysed further, but they nevertheless reveal that users started to appropriate the model implemented in the prototype and to question their own activity.

All these comments were then discussed by the agronomists in Stage 3. They gathered comments which they viewed as belonging to the same cluster in a given column of tahle 2. They then chose two or three issues which allowed them to answer the main problems raised by the users and which had good potential from a scientific point of view. As the users had suggested some solutions, it inspired the researchers to find new ways of

Table 1: which perspective of design do the techniques tackle? 
dealing with data collection (inputs) or with data display (outputs).

For example, as users tested the software against a great diversity of NFT data sets, they understood and pointed out the sensitivity of the outputs to the shape of the data set (e.g. the range of cultivars and environments). The agronomists started to check the sensitivity of their statistical model in relation to the shape of the data set, and to develop adjusted solutions against specific data set ranges. To treat this question, they developed strong cooperation with statisticians to identify how to translate this question into objective criteria of choice.

Table 3: Example of dialogue between agronomists about the actors' questions (STAGE 3 )

Even if the tool is not yet operational for users, interviews carried out during Stage 4 allowed us to highlight the changes the process fostered in users' activity systems.

We registered a first change in the object of users' activities. Several of them said the work on the tool had changed their view of their own work. Whereas they used to focus on cultivar performance in each trial, which gave them a fragmented view of the cultivar behaviour, work with the tool helped them to synthesize the results of the whole NFT differently and in greater depth. In fact they developed a better understanding of what information an NFT could provide when taken in its entirety. They began to see it as a whole from which they could extract comparative information about their cultivars and about the real environmental conditions in which those were tested, and no longer as an assurance that they had tested the cultivars in a priori diverse situations. This also raised new questions about the role of their expertise in constructing the NFT and about the way in which this expertise could be combined with the results given by the tool.

Significant changes also took place in the instrumental part of the system. In fact, the introduction of a new tool in the existing system of instruments led the users to question their whole system of instruments linked with the assessment of cultivar behaviour, namely the experimental field trials, the protocols of measures, and the calculations to interpret those measures. Some changed their global computing system to have more power for processing the results of their field trials. Some systematized the taking of new measurements (meteorological measurements in the field trials for example) that had proven to be relevant to characterize the cultivar behaviour. Because they had tested different NFT with the prototype, some started to consider the optimization of their NFT to improve their efficiency in discriminating their cultivars, which led them to improve their training in statistics and modelling.

Finally, several actors underlined changes in their relationships with colleagues. They quoted easier communication between the different jobs of the same firm and closer relationships with people doing the same job in other firms. One also explained that the use of the software had revealed a need for a new person who could take care of the new information produced by the software. Others explained that this work had given them a different position in their firm: time was allocated to them, in addition to their routine activities, to start methodological reflection.

Partner A: I know we have a weakness here. I don't know if it is only that work [with the tool] that proved it but it contributed to show it, for sure. ...

Users' question: "How can we be sure that the model points out all the limiting factors?"

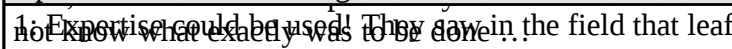
blotch had appeared; they could check if the tool gives the

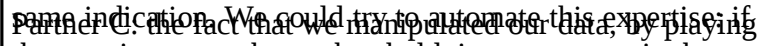

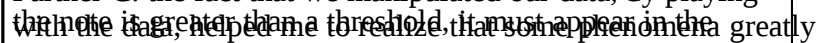

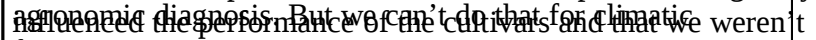
fłetథres taking them into account.

2: It seems to me that it deals with the problem of having criteria to judge the model.

1: It does. And it reminds me of the discussion we had with the statisticians.

2: Is this question a purely statistical question or does it interest the agronomists?

1: In the propositions made by the statisticians, there were things that should count for agronomists: there were important things we have to deal with.

Table 4: Examples of actors' statements in STAGE 4

\section{Analysing crystallization, plasticity and development during the design process}

We would like to present here the first results of an analysis which is still to be worked on. We tried to understand how our three design analysis perspectives crystallization, plasticity and development - occurred and evolved throughout the four stages of the process.

The model of activity crystallized in Stage 1 was reshaped in Stage 3 due to the insight researchers were afforded into data collection problems and users' expertise. They acknowledged that users compensated for the lack of controlled parameters on field trials by their expertise, and used the tool to check or improve such expertise by running it on various data sets with which they were thoroughly familiar and which varied in the number of well controlled parameters. They obtained a picture of a constantly evolving activity. As the users wanted to explore new options (of NFT for example), agronomists also had to clarify the domain of validity of the tool.

The view on plasticity also evolved between Stages 1 and 3 . Researchers not only proposed different outputs to fit the various users' objectives (as in Stage 1), they also started to identify various methods of analysis in order to adjust them to the various data sets of the users. They 
thus moved from a plasticity of outputs to a plasticity of methods.

Developmental issues appeared all along the last three stages. In Stage 2 actors were apparently afforded insight into researchers' points of view as their comments really questioned some key points of the researchers' model. They also questioned their own expertise (e.g. their ability to analyse the effects of climatic limiting factors -LF-), and started to appropriate some functionalities of the tool and to request new ones. In Stage 3 agronomists started to envision their modelling activity differently. They not only adapted the inputs to users' constraints on data collection and the outputs to their objectives, they also questioned their way of analysing data and sorting LF in an NFT. Their picture of the users' activity was thus enriched, and they started to implement it in the tool. Stage 4 was essential to understand further what had occurred for the users

This evolution along these three dimensions of the design process (namely crystallization, plasticity and development) could be related to the techniques we used. As pointed out by Béguin (2007), the analysis of activity (as carried out in Stage 1) mostly addresses crystallization and plasticity issues, while simulation (in Stage 2) can offer opportunities to initiate a development of the users' activity - although this author acknowledges that both can support each dimension. In fact, we suggest that this depends on the way each technique was performed. We directed the analysis of activity towards the study of users' practises, whereas the simulation was meant to afford more insight into the conceptual issues and cognitive tasks around the assessment of cultivars. Therefore, each technique gave some relevant information about users' activities. Moreover, the analysis of activity in Stage 1 was directed towards the concrete work of cultivar assessment whereas the simulation tackled the problem of how to assess the cultivars. It resulted in questioning agronomists' modelling activity differently: in Stage 1 the analysis of activity led to a question about indicators used as inputs of the software, whereas the simulation led to a question about the method to diagnose the yield limiting factors. Simulation, but also the way we carried it out in order to allow each participant to become aware of the points of view of the other participants, apparently stimulated development of both users' and agronomists' activities. This can be related to what Béguin (2003) has already shown in his study of the design and implementation of an alarm system in the chemical industry. He argues that development can occur if the various "professional worlds" and their respective frontiers are acknowledged by the participants of the process and are shaped into a "common world" (which does not mean a shared world). We still need to analyse our data in order to check if users' and researchers' points of view can be qualified as different professional worlds or if, more simply, they are versions of a same professional world. Nevertheless, we argue that recognizing the different versions of a professional world and appropriating them to expand one's own activity is already a step towards development.

\section{Understanding why changes occurred}

We suggest that the changes, whether in the agronomists' way of developing models, in the users' way of assessing cultivars, or in the software itself, are the results of two main features of our design process.

Firstly, the role of collectives cannot be ignored. Part of the mentioned changes occurred because some people that were not used to working together had an opportunity to discuss their way of assessing cultivars' behaviour in NFT. Although various authors argue that collective work on activity in heterogeneous groups of actors is a way to expand activity (Béguin, 2005; Engeström, 2001), explanations vary about how this is achieved. In our situation we are currently analysing our data to check that the emergence of development is the result of at least three design choices. The first one is our way to show the users how agronomists assessed cultivars in an NFT by: (i) explaining to them the model implemented in the prototype and (ii) allowing them to explore its relevance against their databases. The second choice is that even if the actors were requested to test the prototype against their respective databases, we did not check if the prototype could support their current way of assessing cultivars. Instead, we asked them to explore what new information they could extract and assess from the NFT by using the prototype. The third design choice is our way of collecting and analysing the questions raised by actors, and of categorizing them through collective discussions among agronomists.

Secondly, the tool also seems to play a central role as it apparently allowed: (i) the actors to "play" with the agronomists' conception of cultivar assessment; (ii) the agronomists to explore how the actors match their own expertise to the model and raise new questions during its appropriation, (iii) the researchers to decide how to categorize the questions (interface, agronomic, and use problems) raised by the actors. The tool was thus a means to make visible researchers' and users' different points of view on the assessment of the cultivars' behaviour.

We still need to investigate these two features more fully. In particular with regard to the role played by the collective discussions, we would like to study to what extent the various actors became aware of their differing points of view. We would also need to check in greater depth our hypothesis about the causal relation between the way we organized these debates around the tool, and the changes that can be observed in users' activity or at least in their discourses about what has to change.

Finally, we must underline the fact that, even if we observed changes in the activity of each of our three 
groups of participants, the changes that occurred or were said to occur rapidly, were different from one group to another. We suggest that these differences must be analysed according to the political and organizational context of each organization and the framing we managed to implement with each partner. These parameters are not fully controllable but their impacts on the expansive process have to be further analysed.

\section{CONCLUSION}

Sharing the design of a tool between designers (here researchers) and potential users was made possible by promoting debates around the use of a prototype and by giving the opportunity to each participant to become aware of the diversity of the participants' points of view on cultivar assessment.

The choice we made, to give the prototype to users so that they could "play" with it on their respective databases, seems interesting in two respects. Firstly it gave the researchers insight into the cognitive dimensions of users' real work. It secondly gave the researchers some means to enable the users to stand back from their routine work and think about new ways of using their NTF to assess their cultivars. Our design strategy resulted in an in-depth redesign of the tool and fostered changes in activities of both researchers and users. Cognitive activities of the users were notably disturbed, in the way of conceiving an NTF or in the methods used to interpret the data. The researchers' modelling activity and their envisioning of users' activities and of the way to deal with heterogeneous data sets also changed.

Two factors seemed decisive in the observed changes: (i) the dynamics of collective debates on the model, thanks to the use of a prototype, and (ii) the way we suggested the users "play" with the prototype that did not exactly match their routines. We still need to assess the role of these methodological factors in developmental issues more fully. We also wish to examine how the whole strategy created a dynamic in the three dimensions that we were studying: crystallization, plasticity and development. Finally, we need a better assessment of the impact of the framing of our partnership on the diversity of dynamics that we observed among the three organizations we worked with.

\section{ACKNOWLEDGEMENTS}

We wish to thank all the actors who took part in this work, from the GIE Club des 5, from the GEVES and from Arvalis. We are grateful to all of them for their constant availability and their open-mindedness that led them to accept such an unusual kind of research work.

We would also like to thank the reviewers for their comments which enabled us to improve this paper.

\section{REFERENCES}

Béguin, P. (2003). Design as a mutual learning process between users and designers. Interacting with Computers, 15/5, 709-730.

Béguin, P. (2005) La simulation entre experts : double jeu dans la zone proximale de développement et construction d'un monde commun. In : P.Pastré (Ed.), Apprendre par la simulation, De l'analyse du travail aux apprentissages professionnels (pp.55-77). Toulouse: Octares.

Béguin, P. (2007, to be published). L'ergonomie en conception : cristallisation, plasticité et développement. In A. Hatchuel \& B. Weill (Eds.), les nouveaux régimes de la Conception, Paris: Vuibert.

Bodker, S., Gronbaek, K. \& Kyng, M. (1993). Cooperative design: techniques and experiences from the Scandinavian scene. In Schuler D. \& Namioka A. (eds).Participatory Design. Principles and Practices (pp.157-176). Hillsdale, New Jersey: Lawrence Erlbaum Associates

Brancourt-Hulmel, M., Lecomte, C., \& Meynard, J.M. (1999). A Diagnosis of Yield-Limiting Factors on Probe Genotypes for Characterizing Environments in Winter Wheat Trials. Crop Science, 39, 1798-1808.

Engeström, Y. (1987). Learning by expanding: An activity-theoretical approach to developmental research. Helsinki: Orienta-Konsultit.

Engeström, Y. (2001). Expansive Learning at Work: toward an activity theoretical reconceptualization, Journal of Education and Work, 14 (1), 133-156.

Henderson, A. (1991). A Development Perspective on Interface, Design, and Theory. In: J.M. Caroll (Ed.) Designing Interaction, Psychology at the HumanComputer Interface (pp). Cambridge: Cambridge University Press

Lecomte C. (2005). L'évaluation expérimentale des innovations variétales. Proposition d'outils d'analyse de l'interaction génotype - milieu adaptés à la diversité des besoins et des contraintes des acteurs de la filière semences. Doctoral dissertation. INA P-G, Paris, France.

Miettinen, R. (2006). The Sources of Novelty: A Cultural and Systemic View of Distributed Creativity. Creativity and Innovation Management, 15 (2), 173-181.

Prieto, L. J. (1975). Pertinence et pratique. Essai de sémiologie. Paris: Editions de Minuit.

Vygotski, L. S. 1978. Mind in society: The development of higher psychological processes. Cambridge, Mass.: Harvard University Press. 
